Article

\title{
Importance of Blade-Coating Temperature for Diketopyrrolopyrrole-based Thin-Film Transistors
}

\author{
Jun-Ik Park ${ }^{1}$, Hyeon-Seok Jeong ${ }^{1}$, Do-Kyung Kim ${ }^{1}$, Jaewon Jang ${ }^{1}$, In Man Kang ${ }^{1}$, \\ Philippe Lang ${ }^{2}\left(\mathbb{D}\right.$, Yun-Hi Kim ${ }^{3}$, Hyeok Kim ${ }^{4, *}$ and Jin-Hyuk Bae ${ }^{1, *(\mathbb{D}}$
}

1 School of Electronics Engineering, Kyungpook National University, 80 Daehakro, Bukgu, Daegu 41566, Korea

2 ITODYS, CNRS UMR 7086, Université Paris Diderot (Paris 7), 15 rue Jean-Antoine de Baïf, 75205 Paris CEDEX 13, France

3 Department of Chemistry and Research Institute for Natural Science, Gyeongsang National University, 501 Jinjudaero, Jinju, Gyeongnam 52828, Korea

4 Department of Electrical Engineering, Engineering Research Institute (ERI), Gyeongsang National University, 501 Jinjudaero, Jinji, Gyeongnam 52828, Korea

* Correspondence: hyeok.kim@gnu.ac.kr (H.K.); jhbae@ee.knu.ac.kr (J.-H.B.); Tel.: +82-55-772-1718 (H.K.); +82-53-950-7222 (J.-H.B.)

Received: 4 June 2019; Accepted: 2 July 2019; Published: 5 July 2019

\begin{abstract}
In this work, the effect of blade-coating temperature on the electrical properties of a conjugated donor-acceptor copolymer containing diketopyrrolopyrrole (DPP)-based thin-film transistors (TFTs) was systematically analyzed. The organic semiconductor (OSC) layers were bladecoated at various blade-coating temperatures from room temperature (RT) to $80^{\circ} \mathrm{C}$. No remarkable changes were observed in the thickness, surface morphology, and roughness of the OSC films as the blade-coating temperature increased. DPP-based TFTs exhibited two noticeable tendencies in the magnitude of field-effect mobility with increasing blade-coating temperatures. As the temperature increased up to $40{ }^{\circ} \mathrm{C}$, the field-effect mobility increased to $148 \%$ compared to the RT values. On the contrary, when the temperature was raised to $80^{\circ} \mathrm{C}$, the field-effect mobility significantly reduced to $20.9 \%$ of the mobility at $40{ }^{\circ} \mathrm{C}$. These phenomena can be explained by changes in the crystallinity of DPP-based films. Therefore, the appropriate setting of the blade-coating temperature is essential in obtaining superior electrical characteristics for TFTs. A blade-coating temperature of $40{ }^{\circ} \mathrm{C}$ was found to be the optimum condition in terms of electrical performance for DPP-based TFTs.
\end{abstract}

Keywords: organic thin-film transistor; donor-acceptor copolymers; diketopyrrolopyrrole; blade-coating; temperature

\section{Introduction}

Conjugated polymer-based thin-film transistors (TFTs) have generated wide interest for potential use in next-generation displays or bio-sensors on account of their merits such as low processing temperature and mechanical stretchability [1-3]. Solution process-based TFTs are generally cost-effective and less time-consuming due to the simplicity of their fabrication process. In addition, several studies have reported excellent electrical performance of TFTs [4-6]. Meniscus-guided coating, such as blade coating, slot-die coating, and solution shearing, has the advantage of a having a large area with improved growth uniformity and molecular alignment by virtue of unidirectional coating [7-9]. Several investigators have recently turned to donor-acceptor copolymers containing diketopyrrolopyrrole (DPP) semiconductors due to their relatively low bandgap and high mobility [10-12]. Specifically, 29-diketopyrrolopyrrole-selenophene vinylene selenophene (29-DPP-SVS) polymer-based TFTs have been attracting considerable attention because they have a reduced stacking distance and strong 
interaction through appropriate side-chain engineering of the polymer backbone and the branching position of the side-chains [13-15]. The coating temperature is one of the important processing parameters in meniscus-guided coating since the rate of solvent evaporation is controlled by the blade-coating temperature and is related to nucleation and crystal growth rate [16]. However, the effect of the blade-coating temperature on electrical characteristics in 29-DPP-SVS polymer-based TFTs has not been fully analyzed.

In this work, we report the effect of the blade-coating temperature on the electrical properties of polymer-based TFTs with 29-DPP-SVS. As the blade-coating temperature increases, physical analysis results for morphological characteristics of the polymer active layer, such as thickness, surface morphology, and root-mean-square (RMS) roughness, are found to remain unchanged. The devices show two remarkable tendencies on the magnitude of field-effect mobility according to increasing the blade-coating temperature from room temperature (RT) to $80^{\circ} \mathrm{C}$. These phenomena are related to the crystallinity of DPP-based films. The devices show superior crystallographic characteristics and field-effect mobility at a blade-coating temperature of $40^{\circ} \mathrm{C}$.

\section{Materials and Methods}

\subsection{Fabrication Process}

A flow chart of the fabrication process for the 29-DPP-SVS polymer film by blade coating on a large area substrate is shown in Figure 1a. P-type boron-doped Si wafer was used as the gate electrode and $\mathrm{SiO}_{2}$ was thermally grown to achieve a $100 \mathrm{~nm}$-thick layer. The $\mathrm{Si} / \mathrm{SiO}_{2}$ substrate was sequentially cleaned with acetone, isopropyl alcohol, and de-ionized water using an ultrasonicator for $15 \mathrm{~min}$. The 29-DPP-SVS polymer was dissolved in $0.6 \mathrm{wt} \%$ chlorobenzene [17]. The solution was then vigorously stirred at $600 \mathrm{rpm}$ for one day. The blade-coating temperature, which is higher than the boiling point of the solvent, can cause degradation of the polymer film such as pores or pinholes in the active layer during blade coating [18]. In addition, it is difficult to apply coating temperatures above $100{ }^{\circ} \mathrm{C}$ to plastic substrates. Thus, the prepared 29-DPP-SVS polymer solution was blade-coated on the $\mathrm{Si} / \mathrm{SiO}_{2}$ substrate at a speed of $2 \mathrm{~mm} / \mathrm{s}$ with various heating temperatures from $\mathrm{RT}\left(27^{\circ} \mathrm{C}\right)$ to $80^{\circ} \mathrm{C}$ (below the boiling point of the solvent). The blade-coated 29-DPP-SVS polymer thin films were annealed on a hot plate at $200{ }^{\circ} \mathrm{C}$ for $10 \mathrm{~min}$ to remove the residual solvent and fully solidify it [17]. Finally, Au was used as source/drain electrodes with $50 \mathrm{~nm}$ thickness through thermal evaporation under a pressure of $10^{-6}$ Torr and an evaporation rate of $1 \AA / \mathrm{s}$. The channel was patterned with a width and length of 1000 and $500 \mu \mathrm{m}$, respectively, via shadow mask. A cross-section of the completed device and the chemical structure of the 29-DPP-SVS polymer is shown in Figure 1b.

\subsection{Analysis Method}

Cross-sectional images of the films were obtained using field emission scanning electron microscopy (FE-SEM) (S-4800, Hitachi, Chiyoda, Tokyo, Japan) to observe the thickness of the 29-DPP-SVS polymer film. Atomic force microscopy (AFM) (NX20, Park Systems, Suwon, Kyeonggi, South Korea) was used to analyze the surface morphology and roughness. The molecular-state-like crystallinity was measured through grazing incidence X-ray diffraction (GIXD) (D/Max 2500, Rigaku, Shibuya, Tokyo, Japan). The electrical characteristics of the TFTs were extracted and compared using source measure unit (2636B, Keithley, Beaverton, OR, United States) together with a probe station (MSTECH, Hwaseong, Gyeonggi, South Korea) under ambient pressure in a dark space. 


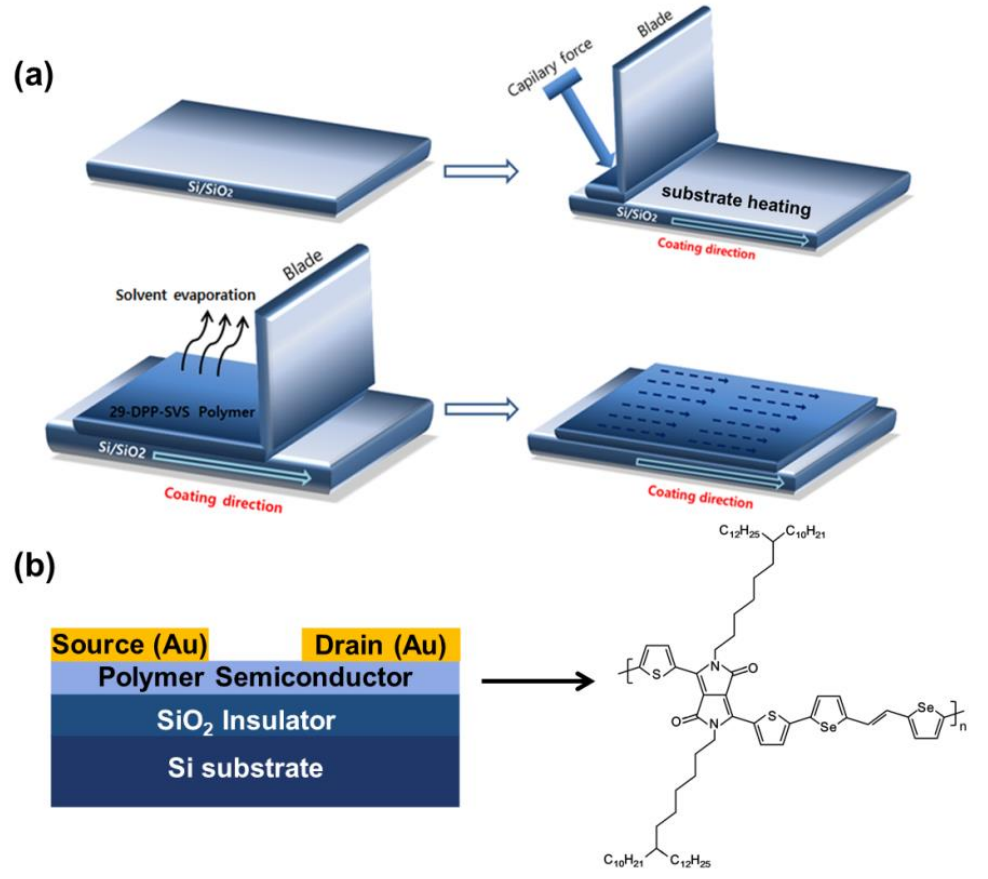

Figure 1. (a) Flow chart of the 29-diketopyrrolopyrrole-selenophene vinylene selenophene (29-DPP-SVS) polymer film fabrication process via blade-coating on a large area $\mathrm{Si} / \mathrm{SiO}_{2}$ substrate. (b) Cross-section of the thin-film transistors (TFT) (staggered bottom gate structure) and chemical structure of 29-DPP-SVS polymers.

\section{Results and Discussion}

\subsection{Thin-Film Analysis}

Figure 2a-d shows cross-sectional FE-SEM images of the 29-DPP-SVS polymer films blade-coated with heated substrates at RT, 40,60 and $80^{\circ} \mathrm{C}$. Regardless of the coating temperature, the 29-DPP-SVS polymer film thicknesses were all around $35 \pm 2 \mathrm{~nm}$. Figure $3 \mathrm{a}-\mathrm{d}$ shows the AFM images and corresponding height profile of the 29-DPP-SVS polymer film as a function of increasing blade-coating temperature. The AFM images exhibited no significant differences in surface morphology. Moreover, they all possessed similar RMS roughness $(0.7 \mathrm{~nm} \pm 3 \AA)$. This reveals that increasing the blade-coating temperature from RT to $80^{\circ} \mathrm{C}$, which is below the boiling point of solvent, has no effect on the thickness and degradation of the surface morphological characteristics of the 29-DPP-SVS polymer film. Thus, there was no significant change in charge injection and extraction efficiency due to the similar surface roughness in the interface between the active layer and the metal. Hence, electrical performance should account for charge transport efficiency in the bulk and channel of the 29-DPP-SVS polymer. Crystallographic characteristics may affect the conductivity associated with charge transport in conjugated polymer films [19].

We performed out-of-plane GIXD analysis to investigate molecular-state-like crystallinity in the 29-DPP-SVS polymer films blade-coated with substrates at different temperatures at a fixed incidence angle $\left(\alpha=0.2^{\circ}\right)$, as shown in Figure 4 . The peak shape in the GIXD is related to the crystallinity, following the Scherrer equation:

$$
D=\frac{K \lambda}{\beta \cos \theta}
$$

where $D$ represents the mean size of the crystalline domains, $K$ is a crystallite shape factor (dimensionless), $\lambda$ is the $\mathrm{X}$-ray wavelength, $\beta$ is the full width at half maximum (FWHM) of the peak intensity, and $\theta$ is the Bragg angle $[20,21]$. As the coating temperature increased from RT to $40{ }^{\circ} \mathrm{C}$, the GIXD spectra showed a sharp peak and reduced FWHM $\left(0.52^{\circ} \rightarrow 0.44^{\circ}\right)$. On the other hand, the peaks tended to become broader and FWHM increased from $0.88^{\circ}\left(60^{\circ} \mathrm{C}\right)$ to $1.04^{\circ}\left(80^{\circ} \mathrm{C}\right)$ when the 
coating temperature exceeded $40{ }^{\circ} \mathrm{C}$. Generally, side chains in organic materials are more affected by thermal treatment than the main backbone [22]. As the blade-coating temperature increases from RT to $40^{\circ} \mathrm{C}$, thermal energy induces structurally more ordered side chains and molecular interactions, which leads to improved crystallinity. However, if the blade-coating temperature exceeds $40^{\circ} \mathrm{C}$, large thermal molecular motions cause weak van der Waals intermolecular interactions, resulting in low crystallinity and randomly ordered molecules [23]. Consequently, the 29-DPP-SVS polymer film blade-coated at a substrate temperature of $40^{\circ} \mathrm{C}$ demonstrated good crystallinity and better defined (00n) reflection peaks with higher-order diffraction peaks up to (003) reflections, as shown in Figure 4.
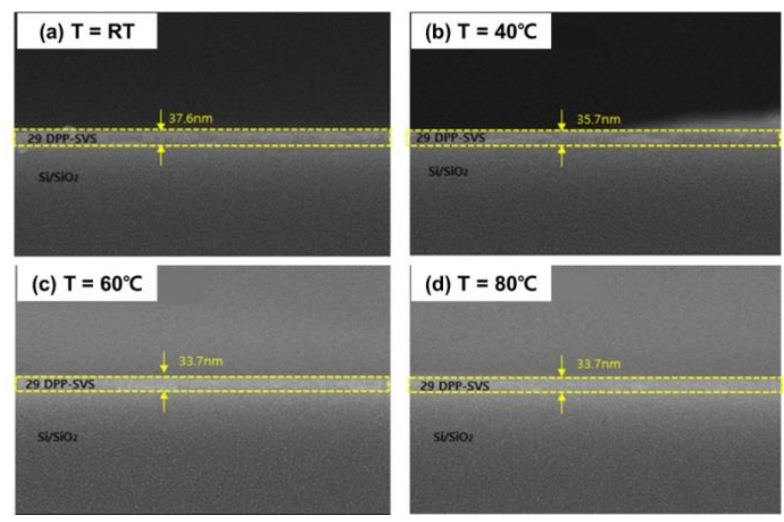

Figure 2. Cross-sectional field emission scanning electron microscopy (FE-SEM) images of 29-DPP-SVS polymer films blade-coated with substrate temperature at (a) RT, (b) $40^{\circ} \mathrm{C}$, (c) $60^{\circ} \mathrm{C}$, and (d) $80^{\circ} \mathrm{C}$.
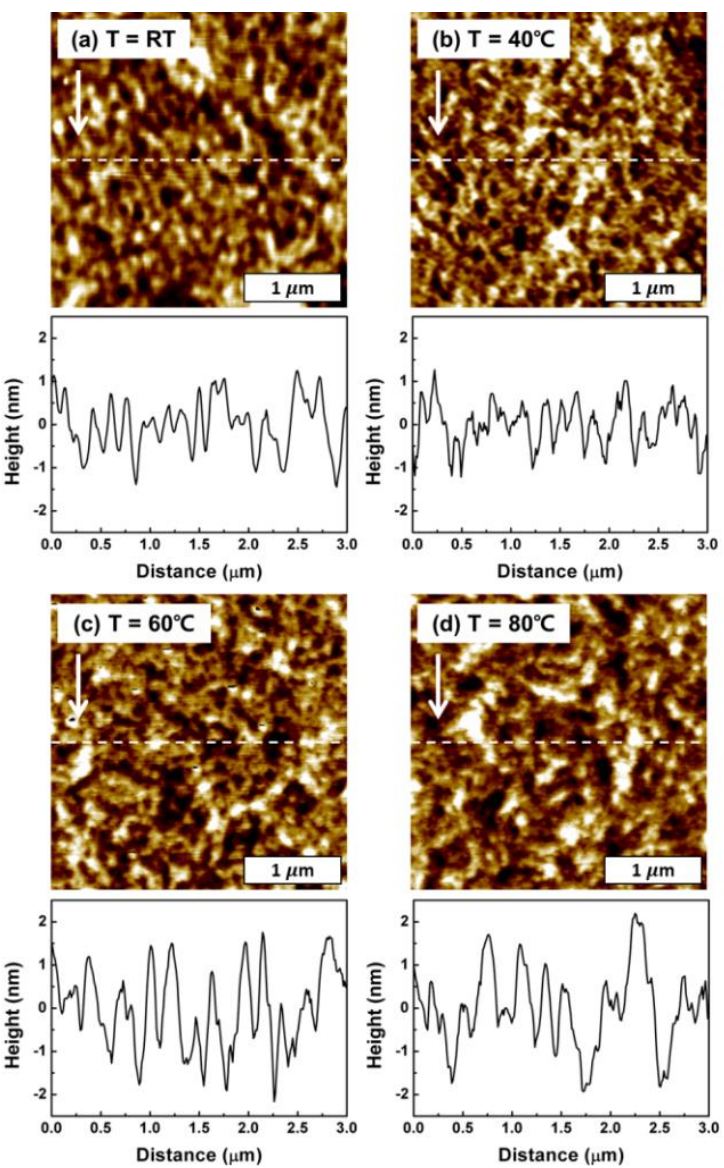

Figure 3. The atomic force microscopy (AFM) images $(3 \times 3 \mu \mathrm{m})$ and corresponding height profile of the 29-DPP-SVS film blade-coated with substrate temperature at (a) RT, (b) $40{ }^{\circ} \mathrm{C},(\mathbf{c}) 60^{\circ} \mathrm{C}$, and (d) $80^{\circ} \mathrm{C}$. The red arrows in the AFM image indicate the blade-coating direction. 


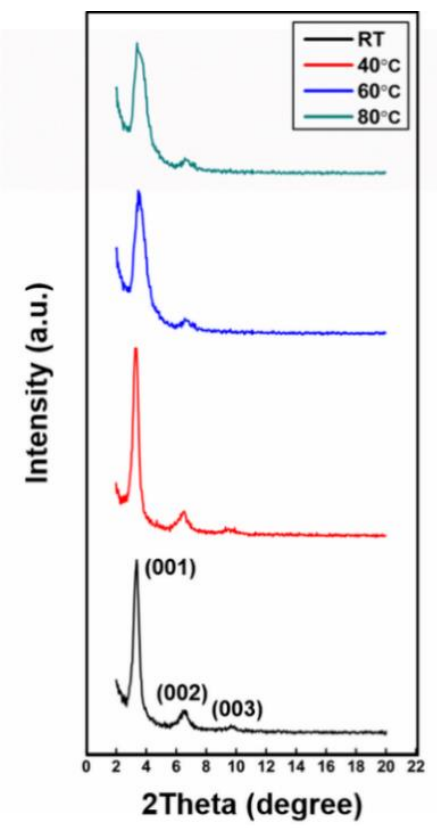

Figure 4. Out-of-plane grazing incidence X-ray diffraction (GIXD) images of 29-DPP-SVS polymer films blade-coated with substrate temperature at RT (black), $40{ }^{\circ} \mathrm{C}$ (red), $60^{\circ} \mathrm{C}$ (blue) and $80{ }^{\circ} \mathrm{C}$ (dark cyan).

\subsection{Electrical Characteristics of TFTs}

Figure 5a shows the output characteristics curves for the TFTs, including the 29-DPP-SVS polymer films blade-coated at different blade-coating temperatures from RT to $80^{\circ} \mathrm{C}$. The devices were operated at a drain voltage $\left(V_{D}\right)$ in a range of $0 \mathrm{~V}$ to $-60 \mathrm{~V}$ and a fixed gate voltage $\left(V_{G}\right)$ of $-40 \mathrm{~V}$. The saturated drain current $\left(I_{\text {Dsat }}\right)$ of the TFT blade-coated at a substrate temperature of $40{ }^{\circ} \mathrm{C}$ yielded the highest value, followed by those blade-coated at $\mathrm{RT}, 60^{\circ} \mathrm{C}$, and $80^{\circ} \mathrm{C}$. The transfer characteristics curve for TFTs blade-coated at different coating temperatures from RT to $80^{\circ} \mathrm{C}$ is shown in Figure $5 \mathrm{~b}$. All the TFTs were operated in the saturation regime by applying a constant $V_{D}$ of $-60 \mathrm{~V}$ and $V_{G}$ in the range of $20 \mathrm{~V}$ to the $-60 \mathrm{~V}$. The field-effect mobility was extracted from the slope of $\sqrt{I_{\text {Dsat }}}$, which is considered as a function of the $\mathrm{V}_{\mathrm{G}}$, using the following equation:

$$
\mu_{s a t}=\frac{2 L}{W C_{o x}}\left(\frac{\partial \sqrt{I_{\text {Dsat }}}}{\partial V_{G}}\right)^{2}
$$

where $\mathrm{L}$ is the channel length, $\mathrm{W}$ is the channel width, and $C_{o x}$ is capacitance per unit area of the $\mathrm{SiO}_{2}$ [24]. Figure $5 \mathrm{c}$ illustrates changes in the magnitude of the average field-effect mobility as a function of increasing blade-coating temperatures from RT to $80^{\circ} \mathrm{C}$. Even if typical polymer-based TFTs exhibit large hysteresis behavior and the estimation of mobility can be unreliable, 29-DPP-SVS polymer-based TFT exhibits very small hysteresis behavior [13]. As the blade-coating temperature increased, the field-effect mobility increased to $4.723 \mathrm{~cm}^{2} \mathrm{~V}^{-1} \mathrm{~s}^{-1}$ at $40^{\circ} \mathrm{C}$ (indicated by Section 1), with a $148 \%$ improvement of the mobility at RT. Subsequently, the mobility decreased to $0.985 \mathrm{~cm}^{2} \mathrm{~V}^{-1} \mathrm{~s}^{-1}$ at $80{ }^{\circ} \mathrm{C}$ (indicated by Section 2), with a reduction to $20.9 \%$ of the mobility at $40{ }^{\circ} \mathrm{C}$. This trend in field-effect mobility coincides with changing crystallinity in the 29-DPP-SVS polymer films at different blade-coating temperatures. For Section 1, the field-effect mobility of the TFT increased because of improved crystallinity due to the thermal energy in the molecule resulting from the increase of the blade-coating temperature from RT to $40^{\circ} \mathrm{C}$, as noted in Section 3.1. However, when the blade-coating temperature was greater than $40{ }^{\circ} \mathrm{C}$ (Section 2), large thermal molecular motions caused weak van der Waals intermolecular interactions. This limited the field-effect mobility due to reduced crystallinity. Furthermore, the higher $I_{D s a t}$ at the same $V_{G}$, obtained by improved crystallinity, led to an increase in the extracted field-effect mobility, consistent with Equation (1). The trends in Sections 1 and 2 were 
consistent with trends in $I_{\text {Dsat }}$, as shown in Figure $5 \mathrm{a}, \mathrm{b}$. Although the other electrical parameters such as threshold voltage and off-current also showed slight variations in the blade-coating temperature, the values were similar within the expected range and there was no remarkable tendency with respect to the blade-coating temperature. As the blade-coating temperature increased from RT to $80{ }^{\circ} \mathrm{C}$, threshold voltages for the TFTs exhibited rather similar values in the range of $2.53 \pm 0.88 \mathrm{~V}$. In order to specifically investigate the correlation between the blade-coating temperature and threshold voltages, we calculated the interface trap density in thin-film transistors using the following equation:

$$
S \equiv \ln 10 \frac{k T}{q}\left(1+\frac{q^{2} D_{i t}}{C_{o x}}\right)
$$

where $S$ is the subthreshold swing and $D_{i t}$ is the interface trap density [25]. The film and electrical characteristics of the devices are summarized in Table 1. As shown in Table 1, there is no correlation between blade-coating temperature and interface trap density and all the TFTs have an equal $\mathrm{SiO}_{2}$ and nearly the same thickness as 29-DPP-SVS polymer films. For this reason, the threshold voltage is independent of the blade-coating temperature. The off-current level had similar values ranging from $10^{-9} \mathrm{~A}$ to $10^{-8} \mathrm{~A}$. When the blade-coating temperature was $40^{\circ} \mathrm{C}$, the 29-DPP-SVS polymer film showed excellent crystallinity and conductivity, so it slightly increased the off-current. In particular, all the devices showed relatively high off-current for $V_{G}$ around $20 \mathrm{~V}$ because the 29-DPP-SVS polymer is an ambipolar polymer semiconductor $[15,26]$. Therefore, the proper setting of the blade-coating temperature is indispensable to achieving superior electrical properties of a TFT. A blade-coating temperature of $40^{\circ} \mathrm{C}$ was found to be the optimum condition to yield the best electrical performance of a 29-DPP-SVS polymer-based TFT.
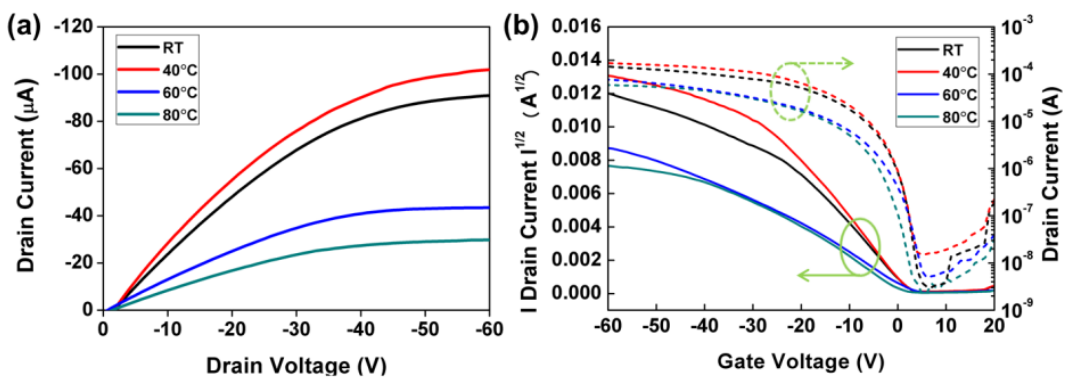

(c)

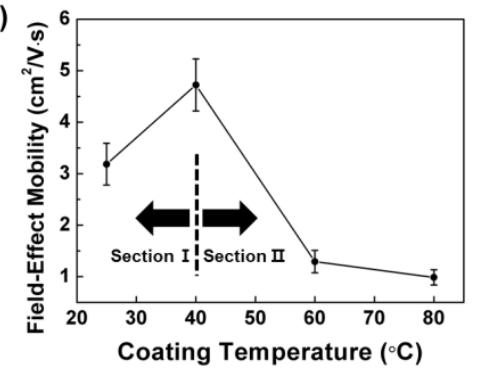

Figure 5. The output (a) and transfer (b) characteristics curves of TFTs blade-coated with substrate temperature at RT (black), $40{ }^{\circ} \mathrm{C}$ (red) $60^{\circ} \mathrm{C}$ (blue) and $80^{\circ} \mathrm{C}$ (dark cyan), respectively. (c) Changes in the magnitude of the average field-effect mobility as a function of different coating temperatures. 
Table 1. The film and electrical characteristics of the DPP-SVS polymer-based TFTs with different blade-coating temperatures.

\begin{tabular}{cccccc}
\hline $\begin{array}{c}\text { Coating } \\
\text { Temperature } \\
\left({ }^{\circ} \mathbf{C}\right)\end{array}$ & $\begin{array}{c}\text { Thickness } \\
(\mathbf{n m})\end{array}$ & $\begin{array}{c}\text { FWHM } \\
\left.\mathbf{(}{ }^{\circ}\right)\end{array}$ & $\begin{array}{c}\text { Field-Effect } \\
\text { Mobility } \\
\left(\mathbf{c m}^{2} / \mathbf{V} \cdot \mathbf{s}\right)\end{array}$ & $\begin{array}{c}\text { Threshold } \\
\text { Voltage } \\
\mathbf{( V )}\end{array}$ & $\begin{array}{c}\text { Interface Trap } \\
\text { Density } \\
\left(\mathbf{c m}^{-\mathbf{2}} \mathbf{e V}^{\mathbf{- 1}} \mathbf{)}\right.\end{array}$ \\
\hline $\mathrm{RT}$ & 37.6 & 0.52 & 3.185 & 2.88 & $6.46 \times 10^{12}$ \\
40 & 35.7 & 0.44 & 4.723 & 2.53 & $7.36 \times 10^{12}$ \\
60 & 33.7 & 0.88 & 1.293 & 3.41 & $8.25 \times 10^{12}$ \\
80 & 33.7 & 1.04 & 0.985 & 1.28 & $7.32 \times 10^{12}$ \\
\hline
\end{tabular}

\section{Conclusions}

We have discussed the effect of blade-coating temperature on the electrical characteristics of 29-DPP-SVS polymer-based TFTs. Thickness, surface morphology, and surface RMS roughness of 29-DPP-SVS polymer films were found to be unaffected by increasing blade-coating temperatures. The devices exhibited two distinct tendencies (Sections 1 and 2) in the magnitude of the field-effect mobility with respect to increasing blade-coating temperatures. These phenomena were attributed to changes in the crystallinity of 29-DPP-SVS polymer films with increasing coating temperatures. The threshold voltage was independent of the blade-coating temperature. The off-current level had similar values but was rather higher due to the improved conductivity and ambipolar properties when the coating temperature was $40^{\circ} \mathrm{C}$. The values of the threshold voltage and off-current in the TFTs were identical for different blade-coating temperatures in the range considered. A blade-coating temperature of $40{ }^{\circ} \mathrm{C}$ was found to produce the optimum condition for peak electrical performance of 29-DPP-SVS polymer-based TFTs. Further studies on various organic semiconductors need to be undertaken to study the complete physical mechanisms necessary to achieve optimal electrical characteristics of TFTs in terms of the processing temperature.

Author Contributions: Conceptualization, H.-S.J., D.-K.K. and J.-H.B.; Data curation, J.-I.P.; Formal analysis, J.-I.P., J.J., I.M.K., H.K., P.L., J.-H.B.; Investigation, J.-I.P. and H.-S.J.; Methodology, J.-I.P., Y.-H.K.; and H.K.; Supervision, H.K. and J.-H.B.; Validation, J.J., I.M.K., P.L., H.K., and J.-H.B.; Visualization, J.-I.P.; Writing-original draft, J.-I.P.; Writing-review and editing, J.-I.P., Y.-H.K., H.K. and J.-H.B.

Funding: This research was supported by Korea Electric Power Corporation (R19XO01-05), Basic Science Research Program through the National Research Foundation of Korea (NRF) funded by the Ministry of Science and ICT (2018R1A2B6008815 and 2018R1A2A1A05078734), and the BK21 Plus project funded by the Ministry of Education, Korea (21A20131600011).

Conflicts of Interest: The authors declare no conflict of interest. The funders had no role in study design, data collection, interpretation, or decision to publish the results.

\section{References}

1. Dimitrakopoulos, C.D.; Malenfant, P.R.L. Organic thin film transistors for large area electronics. Adv. Mater. 2002, 14, 99-117. [CrossRef]

2. Klauk, H. Organic thin-film transistors. Chem. Soc. Rev. 2010, 39, 2643-2666. [CrossRef] [PubMed]

3. Rogers, J.A.; Someya, T.; Huang, Y.; Sorensen, A.E.; Lian, J.; Greer, J.R.; Valdevit, L.; Carter, W.B.; Ge, Q.; Jackson, J.A.; et al. Materials and Mechanics for Stretchable Electronics. Science 2010, 327, 1603-1607. [CrossRef] [PubMed]

4. Sirringhaus, H. Device physics of solution-processed organic field-effect transistors. Adv. Mater. 2005, 17, 2411-2425. [CrossRef]

5. Kang, B.; Lee, W.H.; Cho, K. Recent advances in organic transistor printing processes. ACS Appl. Mater. Interfaces 2013, 5, 2302-2315. [CrossRef] [PubMed]

6. Gelinck, G.H.; Huitema, H.E.A.; Van Veenendaal, E.; Cantatore, E.; Schrijnemakers, L.; Van Der Putten, J.B.P.H.; Geuns, T.C.T.; Beenhakkers, M.; Giesbers, J.B.; Huisman, B.H.; et al. Flexible active-matrix displays and shift registers based on solution-processed organic transistors. Nat. Mater. 2004, 3, 106-110. [CrossRef] [PubMed] 
7. Becerril, H.A.; Mannsfeld, S.C.B.; Bao, Z.; Lee, S.Y.; Toney, M.F.; Aspuru-Guzik, A.; Verploegen, E.; Giri, G.; Kim, D.H.; Atahan-Evrenk, S. Tuning charge transport in solution-sheared organic semiconductors using lattice strain. Nature 2011, 480, 504-508.

8. Diao, Y.; Shaw, L.; Bao, Z.; Mannsfeld, S.C.B. Morphology control strategies for solution-processed organic semiconductor thin films. Energy Environ. Sci. 2014, 7, 2145-2159. [CrossRef]

9. Gu, X.; Shaw, L.; Gu, K.; Toney, M.F.; Bao, Z. The meniscus-guided deposition of semiconducting polymers. Nat. Commun. 2018, 9, 534. [CrossRef]

10. Chang, J.; Chi, C.; Zhang, J.; Wu, J. Controlled growth of large-area high-performance small-molecule organic single-crystalline transistors by slot-die coating using a mixed solvent system. Adv. Mater. 2013, 25, 6442-6447. [CrossRef]

11. Diao, Y.; Tee, B.C.K.; Giri, G.; Xu, J.; Kim, D.H.; Becerril, H.A.; Stoltenberg, R.M.; Lee, T.H.; Xue, G.; Mannsfeld, S.C.B.; et al. Solution coating of large-area organic semiconductor thin films with aligned single-crystalline domains. Nat. Mater. 2013, 12, 665-671. [CrossRef] [PubMed]

12. Li, Y.; Singh, S.P.; Sonar, P. A high mobility P-type DPP-thieno[3,2-b]thiophene copolymer for organic thin-film transistors. Adv. Mater. 2010, 22, 4862-4866. [CrossRef] [PubMed]

13. Kang, I.; Yun, H.J.; Chung, D.S.; Kwon, S.K.; Kim, Y.H. Record high hole mobility in polymer semiconductors via side-chain engineering. J. Am. Chem. Soc. 2013, 135, 14896-14899. [CrossRef] [PubMed]

14. Ryu, G.; Hun, K.; Park, W.; Kim, Y.; Noh, Y. High-performance diketopyrrolopyrrole-based organic field-effect transistors for flexible gas sensors. Org. Electron. 2015, 23, 76-81. [CrossRef]

15. Back, J.Y.; Yu, H.; Song, I.; Kang, I.; Ahn, H.; Shin, T.J.; Kwon, S.K.; Oh, J.H.; Kim, Y.H. Investigation of structure-property relationships in diketopyrrolopyrrole-based polymer semiconductors via side-chain engineering. Chem. Mater. 2015, 27, 1732-1739. [CrossRef]

16. Kim, M.K.; Lee, H.S.; Pae, S.R.; Kim, D.J.; Lee, J.Y.; Gereige, I.; Park, S.; Shin, B. Effects of temperature and coating speed on the morphology of solution-sheared halide perovskite thin-films. J. Mater. Chem. A 2018, 6, 24911-24919. [CrossRef]

17. An, T.K.; Kang, I.; Yun, H.; Cha, H.; Hwang, J.; Park, S.; Kim, J.; Kim, Y.J.; Chung, D.S.; Kwon, S.; et al. Solvent Additive to Achieve Highly Ordered Nanostructural Semicrystalline DPP Copolymers: Toward a High Charge Carrier Mobility. Adv. Mater. 2013, 7003-7009. [CrossRef]

18. Chang, J.F.; Sun, B.; Breiby, D.W.; Nielsen, M.M.; Sölling, T.I.; Giles, M.; McCulloch, I.; Sirringhaus, H. Enhanced Mobility of poly(3-hexylthiophene) transistors by spin-coating from high-boiling-point solvents. Chem. Mater. 2004, 16, 4772-4776. [CrossRef]

19. Kline, R.J.; McGehee, M.D. Morphology and charge transport in conjugated polymers. Polym. Rev. 2006, 46, 27-45. [CrossRef]

20. Scherrer, P. Bestimmung der inneren Struktur und der Größe von Kolloidteilchen mittels Röntgenstrahlen. Kolloidchem. Ein Lehrb. 1912, 277, 387-409.

21. Patterson, A.L. The scherrer formula for X-ray particle size determination. Phys. Rev. 1939, 56, $978-982$. [CrossRef]

22. Bae, J.H.; Park, J.; Keum, C.M.; Kim, W.H.; Kim, M.H.; Kim, S.O.; Kwon, S.K.; Lee, S.D. Thermal annealing effect on the crack development and the stability of 6,13-bis(triisopropylsilylethynyl)-pentacene field-effect transistors with a solution-processed polymer insulator. Org. Electron. 2010, 11, 784-788. [CrossRef]

23. Fratini, S.; Mayou, D.; Ciuchi, S. The transient localization scenario for charge transport in crystalline organic materials. Adv. Funct. Mater. 2016, 26, 2292-2315. [CrossRef]

24. Schroder, D.K. Material and Device Semiconductor Material and Device, 3rd ed.; IEEE Press: Hoboken, NJ, USA, 2006.

25. Lee, S.; Jeon, S.; Nathan, A. Modeling sub-threshold current-voltage characteristics in thin film transistors. IEEE/OSA J. Disp. Technol. 2013, 9, 883-889.

26. Lee, J.; Han, A.R.; Kim, J.; Kim, Y.; Oh, J.H.; Yang, C. Solution-processable ambipolar diketopyrrolopyrroleselenophene polymer with unprecedentedly high hole and electron mobilities. J. Am. Chem. Soc. 2012, 134, 20713-20721. [CrossRef] [PubMed]

(C) 2019 by the authors. Licensee MDPI, Basel, Switzerland. This article is an open access article distributed under the terms and conditions of the Creative Commons Attribution (CC BY) license (http://creativecommons.org/licenses/by/4.0/). 